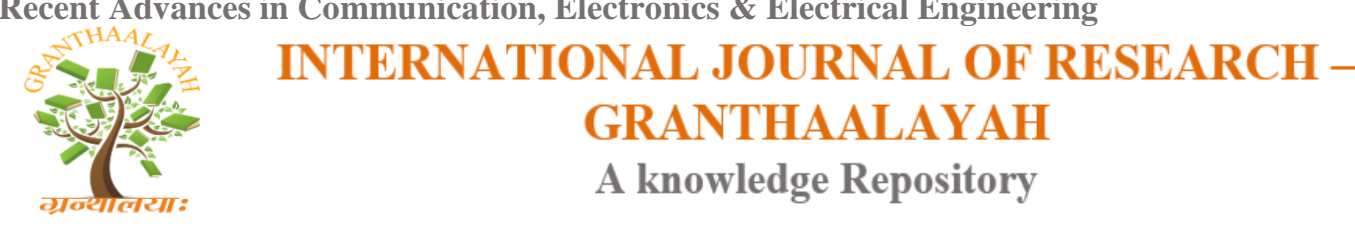

RACEEE - 17

\title{
A STUDY OF ENERGY FLOW AT AN ELECTRICAL SUBSTATION THROUGH ENERGY AUDIT
}

\author{
Darshan. D.A. ${ }^{1}$, Sumith. L.V. ${ }^{2}$, K. Sowjanya Reddy ${ }^{3}$, K. Rasagnya ${ }^{4}$, Trupti, V. N. ${ }^{5}$ \\ *1,2,3,4,5 Electrical \& Electronics Department, School of Engineering \& Technology, Jain \\ University, India
}

DOI: https://doi.org/10.29121/granthaalayah.v5.i4RACEEE.2017.3339

\begin{abstract}
This paper deals with the study of energy flow in a $220 / 66 \mathrm{kV}$ substation. This study emphasizes on energy conservation by reducing power losses. Saving energy is the primary and overwhelming motivating factor for making energy improvements. Energy conservation can increase the environmental quality and higher the savings. Energy conservation lowers the energy costs by preventing future resource depletion (renewable energy source). Utilizing the electric power in the proper manner without wastage is the most important thing to consider. The main objectives are accumulating data at various energy points, identifying energy losses and critical junctions, enabling energy conservation and cost savings. Planning the use of electrical power in the most judicious way such that the usage as well as its wastage is minimized. For this purpose a energy management technique called energy audit is adopted. Energy auditing is required to determine the energy flows through various electrical installations such as feeders, transformers, substations in an electrical network system.
\end{abstract}

Keywords: Energy Conservation; Energy Audit; Energy Management.

Cite This Article: Darshan. D.A., Sumith. L.V., K. Sowjanya Reddy, K. Rasagnya, Trupti, V. N.. (2017). "A STUDY OF ENERGY FLOW AT AN ELECTRICAL SUBSTATION THROUGH ENERGY AUDIT." International Journal of Research - Granthaalayah, 5(4) RACEEE, 161-165. https://doi.org/10.29121/granthaalayah.v5.i4RACEEE.2017.3339.

\section{Introduction}

Electrical power is a critically important component affecting productivity, standard of living, prosperity and strength of any nation. Hence the requirement of electrical power has increased manifolds, but the power generation capacity has not been able to cope up with the demand creating an acute electrical power shortage. This is mainly due to slow rate of increase in power generation, energy pilferages due to large theft of power and transmission and distribution (T\&D) losses, scarcity of the conventional sources of energy generation, poor utilization of non- 
Recent Advances in Communication, Electronics \& Electrical Engineering conventional (renewable) energy sources, speedy increase in the population and its living standards, wastage of power due to the lack of awareness towards energy conservation etc. These reasons, combined with the degradation of power quality have further deteriorated the power shortage, which if not bridged immediately may go out of control. The power shortage could be tackled by adopting technique which is Undertaking the performance analysis of the electrical installations and also adopting energy conservation techniques.

\section{Literature Review}

Auditing provides a precise accounting of the input and output of energy for any desired time period. The system shall be capable of providing customizable management reports of identifying gaps in the energy accounted, consumption trend analysis, segregation of technical and commercial losses area/voltage level/ network. The installed capacity of the station (transformer) was very large compared to the actual load it had to supply. Thus the station was under loaded and underutilized for the major period of its operation. This reduced the operational efficiency of the station. Secondly the incoming line voltage level was remaining high during most of the period of operation. Presently voltage is tried to be maintained by switching ON the line reactors at the receiving and sending ends of this station, switching OFF one the $400 \mathrm{kV}$ incoming lines during off peak loading conditions, thus risking the supply reliability. The previous study emphasizes on the urgent need for improving the power quality, streamlining and optimizing the station capacity, operations and its loading pattern [1]. The power shortage could be tackled by increasing the power generation capacities. The power shortage could be tackled by adopting following techniques:

a. Increasing the power generation capacities.

b. Maintaining a qualitative power supply which is reliable, free from harmonics, and maintained within permissible voltage, power factor and frequency tolerances.

c. Undertaking the performance analysis of the electrical installations and improving their energy efficiency and also adopting energy conservation techniques [2] [3].

Energy is the basic necessity for the economic development of a country. Many functions are necessary to present day living grind to a halt when supply of energy stops. It is practically impossible to estimate the actual magnitude of the past that energy has played in the building up of present-day civilization. The availability of huge amount of energy in the modern times has resulted in a shorter working day, higher agricultural and industrial production, a healthier and more balanced diet and better transportation facilities. There is a close relationship between the energy used per person and his/her standard of living. The greater the per capita consumption of energy in a country, the higher is the standard of living of its people [4].

Electricity is transmitted at high voltages $(110 \mathrm{kV}$ or above) to reduce the energy lost in long distance transmission. Power is usually transmitted through overhead power lines to transmission or sub-transmission substations. Despite the undisputed success of electrical power generation, transmission and distribution all over the world, many important fundamental problems and questions remain unanswered in many utilities dealing with electrical power. Without doubt, one of the most widely discussed of these in the present day is how to conserve electric power and to achieve reliability of electric power [5]. 
Recent Advances in Communication, Electronics \& Electrical Engineering

\section{Energy Audit}

An energy audit is an in depth study of a facility to determine how and where energy is being used or converted from one form another, to identify opportunities to reduces energy usage, evaluate the economics and technical practicability of implementing these reduction. Energy audit is done to formulate priorities recommendations for implementing process improvements to save energy. It means energy audit is a key to a systematic approach for decision making in the area of energy management.

As per the energy conservation act, 2001,"energy audit" is defined as the verification monitoring and analysis of use of energy including submission of technical report containing recommendations for improving energy efficiency with cost benefit analysis and an action plan to reduce energy consumption systematic approach, to monitor industrial energy consumption and to pin-point sources of wastage is known as energy audit.

\section{Need of Energy Audit}

Energy audit is very helpful for improving efficient utilization of available resources. In any manufacturing process or industry, there are some major operating expenses i.e material labour and energy. Energy is a main component of cost structure of any product.

Energy audit helps:

1) To understand which type of fuel is being used in particular process

2) In identifying the quantity and cost of various energy forms.

3) In identifying the energy consumption at various

4) In highlighting wastage by relating energy input and production output.

By improving efficient utilization of available energy resource it reduces the overall cost of product or process which will be a guiding factor in management decisions or laying down management policies.

\section{Methodology}

A suitable substation need to be identified and detail study of each and every electrical component has to be done. The single line diagram of the substation using auto cad software is plotted. Figure 1 shows the flowchart of the process of energy auditing to be done. A walk through survey of the substation is done. Substation audits will be performed to discover where energy is being consumed and wasted.

The detailed methodology of energy audit will be developed during the course of the project using the following approach. 
Recent Advances in Communication, Electronics \& Electrical Engineering

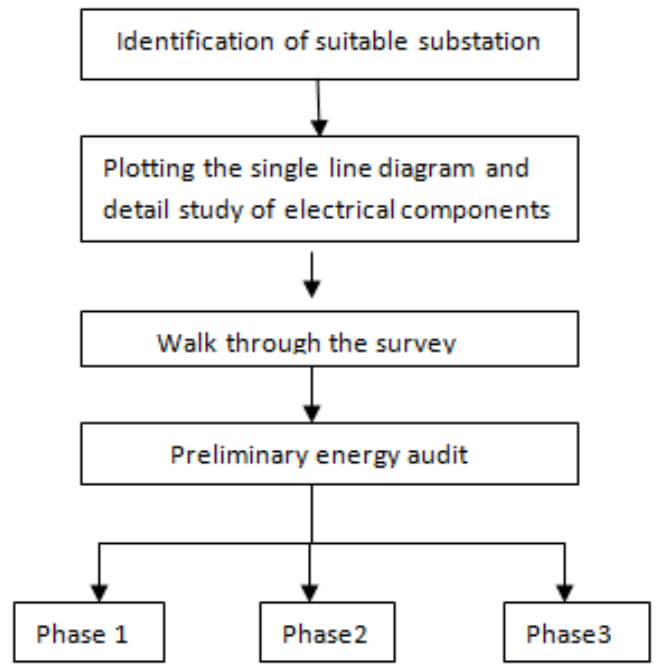

Figure 1: Flow Chart for energy auditing

Energy savings will be determined based on energy measurement (or) energy audit like:

1) Preliminary Energy Audit

2) Detailed Energy Audit

\section{Preliminary Energy Audit:}

Preliminary energy audit is an earlier exercise to detailed audit. It gives the outlook of the overall work.

Preliminary energy audit is carried out to:

1) Find out the scope for saving.

2) Establish energy consumption in the different components.

3) Identify areas where immediate improvements are needed.

4) Establish some input-output performance standards.

5) Find out some of the areas where detailed study is required.

6) Collect the data which is easily available.

\section{Detailed Energy Audit:}

Detailed energy audit is the total examination of an organization or parts of it. It includes checks on the effectiveness of existing system then provides a detailed energy project implements plan.

The main objectives of detailed energy audit can be summarized as follows:

1) To highlight deficiencies in procedures and planning.

2) To suggest improvements in methods of operations.

3) To highlight weak links in internal control system and suggesting improvements.

4) To provide most accurate estimate of energy savings and cost.

Detailed energy auditing is carried out in three phases:

- Phase 1 - Pre audit.

- Phase 2 - Audit phase.

- Phase 3- Post audit. 
Recent Advances in Communication, Electronics \& Electrical Engineering

\section{Phase-1 Pre-Audit Phase Activities:}

This includes initial study of site, which is very useful for planning of future activities.

- Collect the details of all related data about major energy consumption.

- Obtain the site drawing.

- To identify main focus area for energy saving during energy audit.

- To prepare plan for audit.

\section{Phase -2.Detailed Energy Audit Activities:}

Total time required for detailed audit depends on type of industry /site. Detailed Studies to establish and investigate, energy and material balances for specific plant departments or items or process equipment are carried out. Here readings or checks of plant operations are taken at different time, different time intervals to ensure that nothing is overlooked.

Detailed energy audit is carried out by following steps:

- Study of primary data, process flow diagram, energy utility diagram.

- Record some important data conduct survey and monitor the process.

- Collect information about energy and material balance and energy waste in different process/stage.

- Identification and development of energy conservation (ENCON) opportunities by using some important effective techniques.

\section{Phase-3.Post Audit Phase:}

Assist and implement ENCON recommendation measures and monitor the performance. Periodically review the performances of overall system and follow-up.

\section{Conclusion}

This study will help in emphasizing optimal use of energy. Auditing will help in identifying the areas of improvement. From the observed field data and primary data load pattern can be analysed. Based on the observations and detailed analysis suitable suggestion or recommendations can be proposed for energy conservation.

\section{References}

[1] Energy Audit of a 400/220 kV Substation - a Case Study Sunil M. Jaralikar and Mangalpady Aruna

[2] P. W. O'Callaghan and S.D. Probert, "Energy management", Applied Energy, vol. 3, Issue 2, pp. 127-138, April 1977.

[3] Clive Beggs, "Energy audits and surveys", Energy Management and Conservation, pp. 73-91, 2002

[4] Mehta V.K and Mehta R. Principles of Power Systems, New Delhi: S. Chand and company.2000

[5] Electrical Power Substation Energy Audit And The Cost- Benefit Analysis Of Automating Switching Operations During Outages At The Kenya Power Company Limited, MSc dissertation April 2012.

*Corresponding author.

E-mail address: trupti.vrn@gmail.com 